\title{
FRAGMENTOS DA HISTÓRIA DA EDUCAÇÃO NO PARÁ NO INÍCIO DO SÉCULO XX: INSTITUTO GENTIL BITTENCOURT, ORIGEM, ORGANIZAÇÃO E CONCEPÇÕES PEDAGÓGICAS
}

Celita Maria Paes de Sousa

Universidade Federal do Pará

\section{RESUMO}

O presente trabalho é parte de uma pesquisa em andamento que investiga a história da educação feminina no Pará, tendo como foco principal a recuperação da história do Instituto Gentil Bittencourt, instituição destinada a atender, prioritariamente, meninas desvalidas da região, como eram identificadas as meninas órfãs e pobres. Nesta pesquisa temos como delimitação o final do século XIX até os primeiros anos do século XX. Sua metodologia consistiu, no levantamento bibliográfico relativo ao período delimitado para abordar a historiografia da educação feminina paraense. Fontes de estudo primárias e secundárias foram pesquisadas na Biblioteca Arthur Viana e no Arquivo Público do Pará, bem como no acervo do Instituto Gentil Bittencourt. O maior tempo do trabalho de consulta foi dedicado à leitura e análise dos documentos oficiais do governo provincial. $\mathrm{O}$ estudo revelou a concepção de educação fruto da influência religiosa, moral e política da época.

Palavras-chave: Educação feminina; Instituto Gentil Bittencourt; Pará.

\section{FRAGMENTS OF THE HISTORY OF EDUCATION IN PARÁ IN THE EARLY TWENTIETH CENTURY: GENTIL BITTENCOURT INSTITUTE, ORIGIN, ORGANIZATION AND PEDAGOGICAL CONCEPTS}

\begin{abstract}
This work is part of an ongoing study that investigates the history of female education in Pará, focusing mainly on the recovery of the history of the Gentil Bittencourt Institute, an institution meant to serve primarily underprivileged girls in the region, as the orphans and poor girls used to be identified. In this research, the period observed was from the late nineteenth century to the early twentieth century. Its methodology consisted of literature review concerning the delimited period in order to address the historiography of Pará's female education. Primary and secondary sources of study were researched in Arthur Viana Library and the Public Archives of Pará, as well as the Institute Gentil Bittencourt collection. The review focused on reading and analysis of official documents of the provincial government. The study revealed the conception of education as consequence of religious influence, moral and politics of the time.
\end{abstract}

Keywords: Women's education; Institute Gentil Bittencourt; Pará.

\section{Introdução}

O final do século XIX, pleno apogeu do chamado ciclo da borracha na Amazônia, é o momento da criação do Instituto Gentil Bittencourt, em Belém do Pará, substituindo o antigo Colégio Nossa Senhora do Amparo, criado em 1804, por iniciativa do bispo D. Manoel de Almeida Carvalho, para o atendimento de meninas desvalidas. 
É o momento também em que entre os muitos debates na sociedade civil e política no Brasil, um em especial, o dos médico-higienistas, propunha campanhas para "sanear o país", através de projetos de higienização. Esses, conjugados aos projetos de urbanização das cidades brasileiras, postulavam mudanças no campo da saúde e da medicina, vislumbrando a criação de uma nação moderna com indivíduos saudáveis e livres de vícios, pelo uso de boas práticas higiênicas.

Em Belém do Pará, tais ideias encontram eco nos meios políticos e intelectuais, quando essa visão saneadora vai se transformar na proposição de projetos de organização do espaço urbano, que inclui o embelezamento da cidade, aproveitando-se dos amplos excedentes econômicos gerados pela produção e exportação da borracha. Entre as medidas tomadas para concretizar esses objetivos, estão: o combate às epidemias; a reforma do serviço sanitário; o saneamento básico; e a regularização do abastecimento de água encanada. A isso irão se juntar a construção de prédios públicos, pensados e projetados tendo em vista tal concepção saneadora da cidade, atendendo também aos valores estéticos correntes à época.

É assim que, em 1893, através da Lei no 86, de 25 de fevereiro, no governo de Lauro Sodré, o Congresso aprova recursos para a construção de um novo edifício para o Colégio do Amparo, "escolhendo para isso o melhor local, de maneira a preencher todas as condições higiênicas dos internatos e a comportar até trezentas alunas, distribuídas proporcionalmente pelos municípios, afora o acolhimento dos corpos docente e dirigente". ${ }^{1}$ A responsabilidade pela elaboração da planta de um novo prédio é entregue ao engenheiro civil Victor Maria da Silva, vinculado à Secretaria de Obras Públicas.

O terreno escolhido para a construção do novo prédio tem grandes dimensões, localizado numa parte nobre da cidade, onde até então funcionava o Instituto Paraense de Educandos e Artífices. A solenidade de lançamento da sua pedra fundamental aconteceu em 21 de abril de 1894, com a presença de figuras ilustres dos meios políticos, religiosos, intelectuais e militares.

As obras, entretanto, acarretaram grandes gastos aos cofres públicos, o que ocasionou sua paralisação no governo seguinte, de Paes de Carvalho ${ }^{2}$, só tendo sido retomada posteriormente, no governo de Augusto Montenegro.

Ainda no governo de Paes de Carvalho, outra medida importante, logo no seu início, em 1897, foi a mudança da denominação de colégio Nossa Senhora do Amparo para Instituto Gentil Bittencourt, em homenagem ao Dr. Gentil Augusto de Moraes Bittencourt ${ }^{3}$. No mesmo ano, através do decreto $\mathrm{n}^{\circ} 448$, de 06 de julho, o já então Instituto foi reorganizado, estabelecendo-se como sua finalidade dar instrução primária e educação moral e doméstica às órfãs desvalidas. Foi definido ainda que a sua administração ficaria sob a responsabilidade de um diretor, com auxílio de seis membros de um conselho, além de uma regente que seria responsável pela administração interna.

Na virada do século, em 1901, já no governo de Augusto Montenegro, a preocupação em retomar as obras do Instituto Gentil Bittencourt, paralisadas no governo anterior, é demonstrada na mensagem apresentada ao Congresso no início da sua gestão:

Destinado á educação de orphãs desvalidas o Instituto "Gentil Bittencourt" continúa a merecer da parte do governo a mesma attenção com que sempre foi olhado, em respeito ao humanitario fim da instituição (...) Era meu desejo realizar alguns melhoramentos que considero necessários para completar o plano de educação que ahi se de dar, pondoa mais de harmonia com o que rigorosamente deve conhecer uma boa dona de casa, qualquer que seja a sua posição social, e muito especialmente a filha do povo na sua complexa missão de auxiliar o marido, ajudando-o, 
animando-o na lucta pela vida, cuidando da educação dos filhos, tratando, enfim, da economia domestica. ${ }^{4}$

Augusto Montenegro deu continuidade às obras no seu segundo mandato. A prioridade dada à instituição era evidente e se evidenciava nos relatórios do governo, nos quais se identifica a constante preocupação em registrar os gastos e os avanços nas obras.

A edificação do Gentil teve um custo altíssimo para a época que, segundo Vianna, se calcula tenha ultrapassado o valor de 1.300:000\$000 réis. Mas, por outro lado, o autor registra a imponência e a importante localização do prédio:

O Instituto Gentil Bittencourt acha-se majestosamente colocado entre as duas mais belas avenidas desta capital, a Independência e a S. Jerônimo, completamente fechado por um muro de quatro metros de altura, que o separa, à esquerda, de prédios particulares, e à direita, dos imóveis pertencentes à companhia "Pará Electric". O terreno ocupa uma área de 20393 metros quadrados. A sua posição é, pois, a mais desejável para um estabelecimento desta natureza: não está no centro nem fora da cidade, mas num dos bairros mais aristocráticos e higiênicos, sendo facilmente servido pelas duas espaçosas avenidas e por todos os bondes que, partindo da companhia já mencionada, seguem para os mais longínquos pontos da cidade de Belém. ${ }^{5}$

A edificação finalizada por Montenegro estava de acordo com a suntuosidade de outras inauguradas nesse período, que coincide com a intendência de Antonio Lemos na administração da cidade e como parceiro do governador na missão de imprimir nela o padrão de beleza e civilidade tão almejado pelas elites da época. Em vários documentos ${ }^{6}$ foram registrados os avanços alcançados com o novo prédio, solucionando problemas existentes na instituição, desde o primeiro espaço criado pelo bispo D. Manoel, no início do século XIX.

Com a aproximação do fim das obras, Montenegro indica, na mensagem de 07 de setembro de 1905, a necessidade de o instituto passar por uma reforma radical, que incluía as partes administrativa e técnica. ${ }^{7}$ Em linhas gerais, Montenegro expõe aos integrantes do Congresso a sua intenção de entregar a administração interna do instituto a uma ordem religiosa, estabelecendo um contrato com o estado. O instituto continuaria vinculado ao estado e as aulas seriam ministradas pelo corpo de professores do ensino público, enquanto a parte do ensino referente às prendas domésticas seria da responsabilidade da ordem religiosa. A administração superior da instituição deveria ser subordinada ao secretário da Instrução Pública. A autorização é dada pelo Congresso do estado, através da Lei $n^{\circ}$ 946, de 9 de outubro de 1905. E, no dia 21 de novembro do mesmo ano, Montenegro baixa o decreto $\mathrm{n}^{\mathrm{o}} 1405$, contemplando a reforma técnica e administrativa do instituto.

A ordem religiosa escolhida para administrar a instituição foi a das Filhas de Santana, por sua experiência e bom trabalho já desenvolvido no Orfanato Antônio Lemos. Em 16 de novembro de 1905, o contrato foi assinado por Sóror Pierina Della Valle, Provincial da Congregação de Santana, para a prestação de serviço de doze irmãs, junto ao Instituto Gentil Bittencourt. As cláusulas do contrato eram bem definidas quanto às obrigações e responsabilidades das religiosas, e estabeleciam também sua subordinação ao regulamento e orientações baixados pelo Secretário de Estado da Instrução Pública.

Em 20 de junho de 1906, finalmente, o novo prédio do Instituto Gentil Bittencourt é inaugurado pelo governador Augusto Montenegro, para atender duzentas educandas, podendo ser esse número ampliado, de acordo com a necessidade. 


\section{As Marcas da Formação na origem do Colégio Gentil Bittencourt O prédio}

Bela instituição, majestoso edifício, brilhante legado, caprichosa instalação, belo palácio, são, entre tantos outros, os elogios dedicados à beleza arquitetônica do Instituto Gentil Bittencourt, a merecer destaque nos relatórios do governo, nas revistas de ensino, nos periódicos locais. E representava para a cidade um sinal da modernidade, compatível com o projeto de Montenegro e de Antonio Lemos, de embelezamento do espaço urbano de Belém.

A edificação é realmente suntuosa, ocupando uma área de 3.940 metros quadrados, em forma de "E", com vistosa fachada, escadaria em mármore de Carrara e um grande jardim em frente. Na entrada principal, que se abre para um terraço, há uma portaria, a sala de recepção, a secretaria, a capela e uma sala de costura. Possui duas alas laterais com dois pavimentos, cujo pé direito mede de 6,30 a sete metros de altura, e um porão que serve de base para o prédio. Nas alas do térreo encontram-se amplas instalações, com grandes salas de aula, refeitório, enfermaria, farmácia, compartimento com mais de trinta banheiros, salas de banho comum, banho quente e com duchas, cômodos para latrinas e sentinas, salão de rouparia e cômodo para roupas, pátios para recreação, lavanderia, despensa, copa e cozinha, uma sala de refeições das freiras e, nos fundos do terreno, a horta.

O segundo pavimento do prédio também possui duas alas, e nelas ficavam o quarto das freiras, quatro pequenos cômodos, duas privadas, quatro amplos e ventilados dormitórios para as educandas e 92 lavatórios.

Todas as alas têm comunicação entre si e com o prédio principal através de galerias, e com os pátios, através de escadas.

No acabamento do prédio, destaque para alguns materiais empregados, como o mármore da capela e das escadarias; os mosaicos e azulejos dos banheiros, cozinha, refeitório e galerias; e o assoalho de madeiras nobres da Amazônia nos pisos das salas. Alguns desses materiais foram importados da Europa e dos Estados Unidos da América, porém boa parte da mobília foi fornecida pelo Instituto Lauro Sodré ${ }^{8}$.

Os cuidados com a higienização do prédio incluíam o fornecimento de água de boa qualidade, além da instalação de filtros, lavabos, banheiros, latrinas com sifão e tratamento de esgotos.

A preocupação com o problema da higiene, tão criticado nos espaços anteriores do colégio, e os amplos e numerosos espaços construídos parecem revelar a materialização da ideia republicana, configurada num projeto civilizatório de sociedade, no qual a higienização era uma das suas formas mais expressivas.

De modo geral e de outro ponto de vista, poderíamos dizer que a estrutura do prédio estava adequada a uma arquitetura panóptica ${ }^{9}$, com corredores largos, muitas janelas e escadas que, no conjunto, dão visibilidade para as atividades de outros andares e para a área de recreação, permitindo às irmãs observar o que acontecia. $O$ espaço propiciava a vigilância e o controle feito por elas em relação a cada atividade das meninas. Ou seja, isso a que Foucault $^{10}$ chamou de panoptismo, com base nas ideias de Jeremy Bentham, como a possibilidade de observação total das atividades do observado, fazia parte do projeto realizado. E obedecia ao modelo que várias instituições irão adotar por todo o Brasil, nas quais o olhar vigilante garante a ordem.

No Brasil republicano, as instituições para a infância desvalida gradativamente ganham também outros significados, além de referências de espaços, de cuidado e acolhimento, e se fortalecem e se organizam como instituições educacionais. Percebe-se isso, inclusive, para além da atenção dada ao prédio e instalação de objetos e mobília, nas 
expressões simbólicas como as que encontramos no colégio. É o caso de uma lápide comemorativa feita em mármore, na entrada principal, que conta de forma sintetizada a história do instituto, relatando datas e fatos importantes, desde sua criação em 1804 até a inauguração do novo prédio em 1906. E é o caso também do monumento em mármore no jardim à entrada, simbolizando a educação vista como caridade, salvação e futuro das crianças e remédio para todos os males, cujo significado é assim descrito por Vianna:

Sobre um embasamento arquitetural que se apóia em três degraus e que surge entre flores e folhagens, vê-se uma formosa mulher - a instrução pública - indicando a uma criança do povo o Instituto Gentil Bittencourt, onde lhe reservam educação e amparo. $O$ aspecto da criança é de sofrimento e indigência: ela se arrima à grande imagem tutelar, símbolo de toda a civilização humana, como para invocar nesse abandono a graça do seu magnânimo e carinhoso acolhimento. Sôbre os degraus e perto das flôres, no plano mesmo do terreno, duas educandas, com as vestimentas próprias e regulamentares, juvenis e álacres, levam uma coroa de flores e louros como tributo de seu agradecimento pela educação recebida. ${ }^{11}$

\section{A organização e administração}

A partir da lei de 1905, Montenegro promove uma ampla mudança na organização administrativa e técnica do Instituto, para a qual estabelece uma reforma ${ }^{12}$. Por ela fica determinado como finalidade do instituto dar a instrução primária e educação moral e doméstica a órfãs desvalidas, em número de duzentas educandas, com possibilidade do aumento do número de vagas, desde que autorizado pelo Congresso.

O funcionamento do instituto seria fiscalizado pelo Secretário da Instrução Pública, já que a instituição fazia parte do estado. Apenas a administração interna ficaria sob a responsabilidade das religiosas Filhas de Santana, contratadas pelo governo para a prestação de serviços, com as freiras ocupando os seguintes cargos: uma diretora, uma subdiretora, uma farmacêutica, uma porteira e oito auxiliares.

O regulamento era bem claro quanto às obrigações e responsabilidades estabelecidas para cada função. De competência da diretora do instituto: cumprir e fazer cumprir o regulamento; executar as deliberações do Secretário de Estado da Instrução Pública; manter correspondência com o Secretário; zelar pela disciplina no estabelecimento; enviar ao Secretário relatório anual contendo todas as informações necessárias das atividades desenvolvidas no Instituto; fiscalizar as aulas de ensino primário; contratar empregados inferiores, segundo a autorização do governo; organizar uma tabela de custos das obras de costura e prendas; ordenar as compras da administração; organizar uma tabela no final de cada ano, contendo os gastos previstos com alimentação e produtos de higiene; entre outros.

Do mesmo modo, ficavam estabelecidas as funções e responsabilidades dos demais, desde a subdiretora, passando pela farmacêutica e a porteira, até o corpo docente, este composto por quatro professoras normalistas e quatro adjuntas, todas vinculadas ao estado e encarregadas de fazer cumprir o programa adotado pelo Regulamento Geral do Ensino primário. Mesmo a contratação de outros empregados, como cozinheiros, serventes, etc., segundo as necessidades, estaria sujeita à aprovação do governo.

O pagamento do pessoal administrativo e docente seria de responsabilidade do estado, bem como a definição de valores dos vencimentos.

A ideia principal do decreto era, de fato, transferir a administração dos serviços internos do Instituto às religiosas Filhas de Santana, mas o acompanhamento permanente 
nas diversas áreas, desde a administrativa e pedagógica até a moral e religiosa, favoreceria o maior controle pelo estado.

\section{O ensino e o programa curricular}

O instituto estava organizado, prioritariamente, para atender meninas órfãs desvalidas, como ocorria desde o Colégio do Amparo, permanecendo a ideia de que a educação oferecida deveria ser adequada a sua condição social. Por isso, e atendendo às determinações do regulamento, seria ofertado o curso primário, com o acréscimo de cursos de prendas e de serviços domésticos.

O curso primário seria desenvolvido de acordo com o programa prescrito pelo Regulamento Geral de Ensino, objeto do decreto $\mathrm{n}^{\circ}$ 1190, de 17 de fevereiro de 1903, o mesmo adotado nos grupos escolares, ministrado pelas professoras do estado e inspecionado pelos inspetores escolares também do estado.

Os cursos de prendas e serviços domésticos seriam ministrados pelas religiosas Filhas de Santana, de acordo com o programa determinado pela diretoria e aprovado pelo Secretário da Instrução Pública.

Vale ressaltar ainda que no Brasil republicano a educação popular era vista como sinônimo de progresso e, portanto, oferecer educação primária pública à população se definia como base do projeto político recém-inaugurado. Porém, em se tratando de educação para meninas desvalidas, para que não corramos o risco de cometer reducionismos históricos, como bem nos alertam os historiadores José Gondra e Alessandra Shueler ${ }^{13}$, vale a pena tecer mais algumas considerações sobre as condições em que essas práticas educativas se davam e sobre as concepções pedagógicas que as norteavam.

Certamente, durante o período republicano, a administração pública do ensino se voltava para questões relacionadas ao aumento da oferta de vagas, aos métodos e à organização do espaço educativo. Porém, neste caso, o de atendimento de meninas desvalidas no Pará, isso foi vivenciado de forma lenta e peculiar. Assim, a importância dada ao curso primário era bem menor do que aquela dada aos outros cursos, como o de prendas e trabalhos domésticos, por exemplo. Ocorre que as noções de progresso se traduziam de forma diferenciada nesses espaços, já que a concepção de aprendizado escolar para a mulher, aqui em particular para a mulher desvalida, ainda era semelhante a dos oitocentos, com o currículo estruturado segundo sua condição social e direcionado à boa formação para o lar.

Mesmo no período em que José Veríssimo foi diretor geral da Instrução Pública, em 1890, era ainda enfatizada a necessidade de uma redução do plano de ensino para meninas desvalidas. Vianna relata, em linhas gerais, as ideias de Veríssimo sobre o assunto, com as quais ele concorda:

Decretou-se uma redução no plano de ensino, fazendo-o abranger somente o ensino primário e cursos de prendas e serviços domésticos, isto é, o necessário de acordo com o futuro a que se destinam as educandas. ${ }^{14}$

É ainda Vianna, avalizando as ideias de Veríssimo, que conclui pelo equívoco que representou a oferta de algumas disciplinas para as educandas:

Vimos como andou errada a orientação neste assunto, levando os poderes públicos à criação de cadeiras de francês, inglês, piano e dança; é, pois, para louvar que hoje se faça o que desde tanto tempo era preciso fazer restringir o ensino e ampliar a educação doméstica, cívica e moral ${ }^{15}$. 
Desse modo, pelas novas determinações para a organização do ensino, ficava o curso primário dividido em elementar, com a duração de quatro anos, e o complementar, com a duração de dois anos. Para cada turma haveria duas professoras, uma titular e uma adjunta. Essa nova organização trouxe melhoras para o ensino do Instituto, segundo os relatórios do Secretário de Estado do Interior, Justiça e Instrução Pública, Augusto Olympio, encaminhados ao governador em 1909 e 1911. Ocorre que, como o ensino mútuo - aquele em que um professor dava aula para várias séries na mesma turma - era ainda uma realidade muito presente à época, essa possibilidade de poder contar com duas professoras por turma deve ter trazido, realmente, bons resultados para a instituição.

No relatório ${ }^{16}$ apresentado pela superiora, Sóror A. Titã Sbrili, ao Secretário, os dados sobre aprovação no ano de 1909 apontam progressos em relação àqueles obtidos no Colégio do Amparo. O relatório, ao informar que a maioria das meninas fora aprovada, detalha as diferentes categorias nas quais se deu essa aprovação das 227 alunas e, mesmo sem revelar critérios de avaliação para classificação das categorias, indica que as irmãs estavam satisfeitas com o resultado obtido.

Os relatórios do governo dessa época, diferentemente dos anteriores, fornecem poucos dados quantitativos, como, por exemplo, os de matrícula e saída das alunas da instituição. Mas indicam que as turmas chegavam a ter em média de 38 a 58 meninas nas séries do curso elementar, enquanto as da complementar, normalmente tinham quinze alunas.

Os cursos de prendas e serviços domésticos, de responsabilidade das religiosas, eram levados com todo rigor, exigindo intensa dedicação das meninas nas atividades realizadas, pois se acreditava que esse era o caminho para a formação de moças preparadas para serem boas mães e esposas.

O produto das atividades de prendas realizadas pelas alunas era utilizado, em parte, para o uso da própria instituição, e outra, disponibilizada para venda. Com a venda das peças, o dinheiro era revertido para a compra de materiais para as aulas. Havia um livro específico para as anotações dessas receitas e despesas.

As aulas de prendas domésticas eram divididas em dois grupos: o de principiantes, e outro, das mais adiantadas. Todas as alunas tinham de frequentar essas aulas, com exceção daquelas que ainda eram muito pequenas.

Pela descrição dos relatórios da instituição, percebe-se que havia uma rígida disciplina a ser seguida em sua rotina, onde a alternância do trabalho com o descanso, o canto e o exercício físico estabelece um sistema de controle sobre os corpos, bem no sentido de que nos fala Foucault, quando ele vê o corpo como objeto e alvo de poder:

(...) corpo que se manipula, se modela, se treina, que obedece, reponde, se torna hábil ou cujas forças se multiplicam (...) corpo útil, corpo inteligível (...). É dócil um corpo que pode ser submetido, pode ser utilizado, que pode ser transformado e aperfeiçoado ${ }^{17}$.

As aulas de costura ocorriam quinzenalmente e nelas as meninas realizavam algumas tarefas, como fazer os vestidos e aventais, entre outros. Além disso, havia a aula de rouparia, onde se aprendia a consertar e engomar roupa, menos a lavagem que era feita por lavadeiras contratadas, por ser considerado um serviço pesado para as meninas.

O serviço de cozinha, no qual a cada semana ficava um grupo de quatro meninas ou mais em rodízio, também fazia parte do currículo e tinha o objetivo principal de ensiná-las a preparar o mais comum e necessário à refeição de uma família. 
A rotina da cozinha, monótona e cansativa, normalmente era cumprida pelas meninas maiores, que realizavam as atividades de fogão. Em vários momentos tinham que contar com mais ajudantes, pois o volume de trabalho era grande para atender um número que ultrapassava o de duzentas refeições servidas, além da lavagem das louças utilizadas, exigindo muito esforço e disciplina. Enfim, todos os serviços domésticos realizados na instituição eram feitos pelas alunas com ajuda e supervisão rigorosa das irmãs.

Outras aulas ainda eram realizadas na instituição, como música, canto e desenho, mas não tinham o caráter obrigatório. As meninas eram escolhidas para participar segundo suas aptidões, por critérios estabelecidos pelas irmãs, fundados em valores morais e de comportamento.

O valor atribuído a essas aulas tinha um caráter de prêmio pelo bom comportamento e esmero nos estudos, e, ao que parece, as mais pobres e desvalidas não se enquadravam no critério de "boa família" para participar delas.

Quando Foucault discute as formas de "sanção normalizadora" na escola diz que ela pode ser aplicada através de micropenalidade, em casos, por exemplo, como o de um aluno que não se comporta segundo as normas estabelecidas ou não apresenta resultados esperados pelo educador nas atividades em que esteja envolvido. A punição pode ser aplicada através de processos sutis, como a privação de algo, que bem poderiam ser as aulas de música e canto, das quais muitas educandas eram excluídas por não se enquadrarem nos parâmetros que orientavam as normas e os critérios estabelecidos pela instituição ${ }^{18}$.

Das aulas de desenho, tal qual ocorria nas de música e canto, poucas alunas participavam, pois, segundo a irmã superiora, a maioria não atendia ao principal critério para fazê-lo.

A atividade que menos despertava o interesse era a desenvolvida na oficina de tipografia, o que levou à redução da turma para vinte meninas.

A irmã Titã, ao concluir seu relato sobre o ensino na instituição, fazia algumas avaliações sobre o currículo, considerando-o adequado para atender às necessidades das educandas. Porém, apontava a necessidade de se incluir a aula de francês, pois avaliava como fundamental que as meninas soubessem pelo menos uma língua estrangeira, e ressaltava ainda a importância de incluir também aula de educação física.

A rotina organizada e controlada estabelecia um tempo definido para acordar, tomar as refeições, dormir, rezar, estudar, realizar serviços domésticos e tudo mais. As meninas, logo ao acordar, seguiam para o banho. A instituição tinha água encanada e tratada e banheiros suficientes para atender à demanda, com chuveiros em boxes individuais que não possuíam portas, mas apenas uma cortina a preservar a intimidade das alunas. As irmãs vigiavam esse momento do banho, e a inexistência de portas facilitava a fiscalização que elas julgavam necessária. Além do que, culturalmente, era hábito, até os meados dos novecentos, na maioria das instituições de religiosas, as alunas tomarem banho de combinação ${ }^{19}$.

Novamente esses procedimentos parecem revelar aquilo que Foucault chama de "escrúpulos infinitos de vigilância que a arquitetura transmite por mil dispositivos sem honra" ${ }^{20}$, neste caso a vigilância sobre o corpo feminino, considerado sagrado. E que, por isso, precisava ser preservado de todos os apelos sexuais e de pensamentos impuros, seguindo o exemplo de Maria, mãe de Jesus, em cuja pureza e maternidade era preciso se espelhar.

Os horários das rezas e missas faziam parte do ritual religioso, juntamente com outras atividades, como o catecismo, o ato de confissão, as novenas, o terço e as homenagens aos santos. 
As refeições eram feitas três vezes ao dia, num momento compartilhado pelas alunas no grande refeitório. E o cardápio, simples e diferente para cada período, era preparado por um grupo de alunas sob a supervisão das irmãs.

A rotina das aulas estabelecia o horário da manhã para o curso primário e o da tarde para as de prendas. As alunas eram divididas por turma e por série. A partir de 1908, a mesma série seria dividida em duas turmas. As alunas mais adiantadas ficavam com a professora titular e as mais atrasadas ficavam com a professora adjunta. Esta medida foi adotada, segundo a irmã Titã, para melhorar o rendimento das alunas, a partir das dificuldades de cada grupo. A aula de desenho acontecia às terças-feiras à tarde, e a de canto nas quintasfeiras à tarde.

As alunas tinham dois horários para a recreação. Brincavam nos pátios cobertos e na área descoberta, sob a observação das irmãs. No final do dia havia a reza da noite, em seguida as meninas iam para seus quartos e, quando a sineta tocava, as luzes se apagavam.

Aos domingos a rotina era diferente, com um horário especial, que destinava tempo maior para a recreação, além daquele destinado ao estudo e às lições de catecismo. Mas as alunas não tinham permissão para sair, pois era necessário evitar ao máximo o contato com o mundo externo, além dos muros da instituição, onde estava o pecado e os apelos de uma vida desregrada, segundo os valores morais da igreja obedecidos pelas irmãs.

Poucas coisas aconteciam no Instituto, além dessa rotina estabelecida, que mantinha as meninas ocupadas, sem ociosidades, num regime semelhante ao do claustro, necessário para ocupar também seus pensamentos, evitar desejos e controlar seus corpos, com uma disciplina que os tornassem dóceis ${ }^{21}$. Aqui, mais uma vez, recorremos a Foucault, naquilo que ele compreende como "disciplinas", para explicar o rigor com o controle exercido sobre as atividades das alunas:

Esses métodos que permitem o controle minucioso das operações do corpo, que realizam a sujeição constante de suas forças e lhes impõem uma relação de docilidade-utilidade, são os que podemos chamar as "disciplinas". (...) Forma-se então uma política das coerções que são um trabalho sobre o corpo, uma manipulação calculada de seus elementos, de seus gestos, de seus comportamentos ${ }^{22}$.

Há um rico acervo iconográfico (fotografias) nos arquivos que consultamos, que permitem visualizar tudo o que aqui dissemos sobre a natureza "panóptica" dos espaços físicos e do controle e disciplina existentes no Instituto Gentil Bittencourt. Mas, com toda a rigidez existente, a instituição era sempre elogiada pela sua organização, pela higiene e pelos progressos na formação das desvalidas, inclusive por Augusto Montenegro, nos relatórios oficiais do final de seu governo, em 1909.

Ao longo do tempo, a instituição ${ }^{23}$ se modifica e busca alternativas de funcionamento. Na mensagem de 1911, o governador, João Coelho, registra essa preocupação:

Circumstancias superiores á minha vontade obrigam-me a dizer-vos que não pôde ser determinada a conclusão, por vós auctorizada, da ala direita do edifício occupado por este Instituto, a qual destinávamos ao funccioanamento de um externato e semi-internato para alumnas pagantes. (...) Vimos atravessando situação financeira melindrosa e, ao tempo que me esforçava por honrar os compromissos do passado e manter em dia os do presente, não devia esquecer o futuro, augmentando os encargos do thesouro sem que bem solida estivesse sua fortuna. (...) 
Continuo, porém, certo da sua utilidade e, se me não couber a satisfacção de leval-a a effeito, possa outro fazel-o e prestará serviço relevante a esta sociedade, que sente a carência de um estabelecimento em pé de igualdade com este Instituto, para a educação das futuras mães de familia ${ }^{24}$.

Mas o governo de João Coelho logo passou a enfrentar uma crise na esfera política e econômica. Grupos políticos se enfrentavam, o clima era de agitação, ocasionando ataques pela imprensa e violência verbal da população, a que se juntavam os sinais da derrocada do ciclo da borracha na Amazônia, amplificando as dificuldades do governo.

De todo modo, o instituto continuou atendendo, por um longo período, meninas órfãs e pobres, vendo crescer seu prestígio junto à opinião pública, a cada ano aumentando os pedidos de admissão, consolidando-se como referência na Amazônia.

\section{As educandas}

As educandas, egressas de uma vida de pobreza ou de orfandade, eram meninas brancas, pardas, mestiças e caboclas que, ainda muito pequenas, buscavam, no instituto, acolhimento e proteção. Na sua maioria, oriundas de diferentes regiões do Pará, habitantes ribeirinhas, da floresta ou da cidade.

As educandas pobres e/ou órfãs que ingressavam no Instituto Gentil Bittencourt eram as chamadas desvalidas, condição estabelecida no seu Regulamento para o ingresso. No caso das meninas que não eram órfãs, tinham que ser filhas de pais completamente desvalidos, ou seja, num estágio extremo de pobreza. Entretanto, era permitido também o ingresso de vinte educandas que não fossem órfãs.

Outros pré-requisitos exigidos pelo regulamento para admissão eram: não sofrer de moléstia contagiosa e ser maior de sete anos e menor de doze. A comprovação desses dados tinha de ser feita por autoridade judiciária, por médicos e pela certidão ou outro comprovante de idade.

As educandas, ao ingressarem na instituição, recebiam "seis mudas completas de roupas de casa e duas mudas de roupas para passeios; toalhas de rosto, de banho, lenços, calçado para casa e passeios, lençóis, cobertores, chapéus, escovas de dente, pentes" ${ }^{25}$, e tudo o mais necessário para sua rotina de higiene pessoal.

Após a entrada, as educandas eram examinadas e depois vacinadas ou revacinadas contra varíola. O período de férias ficava compreendido entre 25 de dezembro e 07 de janeiro.

O regulamento estabelecia também em quais casos as educandas poderiam ser desligadas da instituição, a saber: " $1^{\circ}$ - por moléstia que as impossibilite de aprender; $2^{\circ}$ por mau comportamento; $3^{\circ}$ - por falta de aproveitamento; $4^{\circ}$ - por conclusão do tempo de estudo e de idade; $4^{\circ}$ por conveniência de ensino; $5^{\circ}$ - pelo casamento" 26 .

As educandas não podiam permanecer na instituição após os dezoito anos de idade. No caso específico de não ter parentes para recebê-la, o governo deveria se responsabilizar pelo seu futuro, providenciando um trabalho. Em certos casos, algumas alunas foram contratadas, depois de concluir o curso primário, com sucesso, para serem professoras adjuntas na instituição, tendo seus vencimentos recolhidos à Caixa Econômica, em cadernetas abertas em seus nomes. No novo regulamento não se contemplava mais o dote às educandas. Acredita-se que, de fato, ele tenha deixado de existir, pois os relatórios oficiais do governo e do instituto não o mencionavam mais. 


\section{Considerações finais}

Os excedentes econômicos do ciclo da borracha na Amazônia, conjugados às novas ideias em discussão no final dos oitocentos e início dos novecentos, bem como a existência de uma elite governante favorável a essas ideias, foram fatores que contribuíram para a criação do Instituto Gentil Bittencourt nos moldes em que foi implantado.

A arquitetura adotada na construção de instituições educacionais como o Gentil Bittencourt revela a preocupação republicana com a educação, buscando atender às demandas de seus interesses e das novas propostas pedagógicas que então surgiam.

Essas novas concepções sobre educação do início dos novecentos, que começavam a questionar a interferência e tutela religiosa nas instituições educacionais, levam o estado, ao contratar os serviços de religiosas, a subordiná-los às normas estabelecidas, que não permitiam a interferência eclesiástica na condução do processo e reafirmavam o instituto como pertencente essencialmente a ele.

A permanência do pensamento positivista de ordem e progresso, imposta e perceptível em todas as áreas físicas e de funcionamento do instituto, também fazia parte do rigoroso controle periódico e sistemático sobre a administração interna e externa da instituição, e se estendia ao controle rigoroso, "panóptico", da disciplina sobre as educandas.

Dentro ainda das concepções pedagógicas do período, o objetivo principal da educação de desvalidas deveria ser adequado à sua condição social e, portanto, dar ênfase à educação doméstica, cívica e moral, com currículo específico, onde a importância maior cabia ao ensino das prendas e serviços domésticos, visando à formação de boas esposas e mães.

Apesar de todo o excesso disciplinador, fruto das concepções religiosas, morais e políticas, o instituto estabeleceu um legado de inestimável valor para a história da educação no Pará.

\section{Referências}

AZZI, Riolando (org.). A vida religiosa no Brasil: enfoques históricos. São Paulo: Paulinas, 1983.

FARIA FILHO, Luciano Mendes de. A infância e sua educação: materiais, práticas e representações (Portugal e Brasil). Belo Horizonte: Autêntica, 2004.

FOUCAULT, Michel. Vigiar e punir: nascimento da prisão. 37 ed. Petrópolis, RJ: Vozes, 2009.

FREITAS, Marcos Cezar de. História social da infância no Brasil. 4. ed. São Paulo: Cortez, 2001.

GONDRA, J. G. \& SCHUELER, A. Educação, poder e sociedade no império brasileiro. São Paulo: Cortez, 2008.

PARÁ. A Educação no Pará: documentário. Belém: SEDUC, 1987.

Álbum do Pará (1901 - 1909: A. Montenegro). Paris: Chaponet, 1908.

SOUSA, Celita $\mathrm{M}^{\mathrm{a}}$ Paes de. Traços de compaixão na história do Pará: instituições para meninos e meninas desvalidas no século XIX até o início do século XX. Tese de doutorado (Educação: currículo). São Paulo, PUC, 2010. 
VIANNA, Arthur. A Santa Casa de Misericórdia Paraense: notícias históricas (1650/1902). $1^{a}$ ed (1906), $2^{a}$ ed. Belém: SECULT, 1992.

\section{LEVANTAMENTO DAS FONTES PRIMÁRIAS:}

a) Impressos de textos legais

PARÁ. MENSAGEM dirigida em 5 de fevereiro de 1900 ao Congresso Legislativo do Pará, pelo José Paes de Carvalho. Governo do Estado do Pará. Belém: Imprensa Oficial do Estado do Pará, 1900.

.MENSAGEM dirigida em 1 de fevereiro de 1901 ao Congresso Legislativo do Pará, pelo José Paes de Carvalho. Governo do Estado do Pará. Belém: Imprensa Oficial do Estado do Pará, 1901.

.MENSAGEM dirigida em 10 de setembro de 1901 ao Congresso Legislativo do Pará, pelo Augusto Montenegro. Governo do Estado do Pará. Belém: Imprensa Oficial do Estado do Pará, 1901.

.MENSAGEM dirigida em 7 de setembro de 1902 ao Congresso Legislativo do Pará, pelo Augusto Montenegro. Governo do Estado do Pará. Belém: Imprensa Oficial do Estado do Pará, 1892.

.MENSAGEM dirigida em 7 de setembro de 1903 ao Congresso Legislativo do Pará, pelo Augusto Montenegro. Governo do Estado do Pará. Belém: Imprensa Oficial do Estado do Pará, 1903.

.MENSAGEM dirigida em 7 de setembro de 1904 ao Congresso Legislativo do Pará, pelo Augusto Montenegro. Governo do Estado do Pará. Belém: Imprensa Oficial do Estado do Pará, 1904.

.MENSAGEM dirigida em 7 de setembro de 1905 ao Congresso Legislativo do Pará, pelo Dr. Lauro Sodré. Governo do Estado do Pará. Belém: Imprensa Oficial do Estado do Pará, 1905.

.MENSAGEM dirigida em 7 de setembro de 1906 ao Congresso Legislativo do Pará, pelo Augusto Montenegro. Governo do Estado do Pará. Belém: Imprensa Oficial do Estado do Pará, 1906.

.MENSAGEM dirigida em 7 de julho de 1907 ao Congresso Legislativo do Pará, pelo

Augusto Montenegro. Governo do Estado do Pará. Belém: Imprensa Oficial do Estado do Pará, 1907. 
${ }^{1}$ VIANNA. op. cit. p. 20.

${ }^{2}$ Além da construção do prédio para as educandas, estava sendo construído um prédio novo para abrigar os meninos do Instituto dos Educandos e a penitenciária da cidade. Cf. VIANNA. op. cit.

${ }^{3}$ Gentil Augusto de Moraes Bittencourt foi um importante republicano do Pará e um dos fundadores do Clube Republicano. Nasceu no município de Cametá (Pará), no distrito de Carapajó, em 22/09/1847. Em 1873, em Recife, se formou obtendo o grau de bacharel em Direito. Durante muitos anos foi provedor do colégio do Amparo, desempenhando com muita dedicação este cargo na instituição de meninas desvalidas. Cf. OLIVEIRA, Hélcio. O sesquicentenário de Gentil Bittencourt. A Província do Pará, 1998, p. 10.

${ }^{4}$ MENSAGEM, 1 de fevereiro de 1901, p.57.

${ }^{5}$ VIANNA, Arthur, 1906, p.23-24.

${ }^{6}$ Cf. MENSAGEM, 1906; 1907; 1908. VIANNA. op. cit.

${ }^{7}$ MENSAGEM, 1905, p. 53

${ }^{8}$ O Instituto Lauro Sodré atendia a meninos desvalidos e desenvolvia diversas atividades em oficinas de profissionalização. A produção da instituição era considerada de alta qualidade.

${ }^{9}$ O panóptico foi um termo utilizado pelo filósofo inglês Jeremy Bentham no século XVIII, que consistia num modelo de arquitetura para as prisões. A ideia central do desenho arquitetônico era possibilitar a vigilância e observação dos prisioneiros. O modelo serviu de exemplo para outras construções como hospitais, fábricas, escolas e outros.

${ }^{10}$ Michel Foucault, em seu livro intitulado "Vigiar e Punir", utilizou o termo para abordar o tema "sociedade disciplinar".

${ }^{11}$ VIANNA. op. cit. p. 32.

${ }^{12}$ A nova reforma foi regulamentada pelo Decreto $\mathrm{n}^{\mathrm{o}}$ 1405, de 21 de novembro de 1905. Abordaremos neste item a organização e a rotina da instituição, tendo em vista as novas determinações estabelecidas no Regulamento.

${ }^{13}$ Cf. GONDRA \& SHUELER, 2008, p.9.

${ }^{14}$ VIANNA. op. cit. p. 40.

${ }^{15}$ Ibid.

${ }^{16}$ Cf. Relatório do Instituto Gentil Bittencourt referente ao ano de 1909.

${ }^{17}$ FOUCAULT, Michel, 2009, p. 132.

${ }^{18}$ Cf. FOUCAULT. op. cit.

${ }^{19}$ Combinação era um tipo de roupa fina usada embaixo dos vestidos.

${ }^{20}$ Ibid., p. 167.

${ }^{21}$ Cf. FOUCAULT. op. cit.

${ }^{22}$ FOUCAULT. op. cit. p. 133.

${ }^{23} \mathrm{O}$ Instituto Gentil Bittencourt, com o tempo, começa gradativamente a reduzir o atendimento de meninas desvalidas, com a inclusão de alunas pagantes. A partir de 1958, as educandas pobres são transferidas para o Orfanato Antônio Lemos, no município de Santa Isabel. E a partir de 1972 passa a atender meninos e meninas. Atualmente o colégio atende desde a educação infantil até o ensino médio.

${ }^{24}$ MENSAGEM, 1911, p. 35-36.

${ }^{25}$ MONTENEGRO, Augusto. Álbum do Pará. 1909, p. 301.

${ }^{26} \mathrm{Cf}$. Regulamento autorizado pelo governador Augusto Montenegro, aprovado através do decreto $\mathrm{n}^{\circ} 1405$, de 21 de novembro de 1905.

Recebido: mai/15 $\quad$ Aprovado: jun/15 